This item was submitted to Loughborough's Research Repository by the author.

Items in Figshare are protected by copyright, with all rights reserved, unless otherwise indicated.

\title{
A framework for filtering web accessibility guidelines
}

PLEASE CITE THE PUBLISHED VERSION

PUBLISHER

(c) ACM

VERSION

AM (Accepted Manuscript)

LICENCE

CC BY-NC-ND 4.0

REPOSITORY RECORD

Baguma, Rehema, R.G. Stone, Jude T. Lubega, and Th.P. van der Weide. 2019. "A Framework for Filtering Web Accessibility Guidelines". figshare. https://hdl.handle.net/2134/4696. 
This item was submitted to Loughborough's Institutional Repository (https://dspace.lboro.ac.uk/) by the author and is made available under the following Creative Commons Licence conditions.

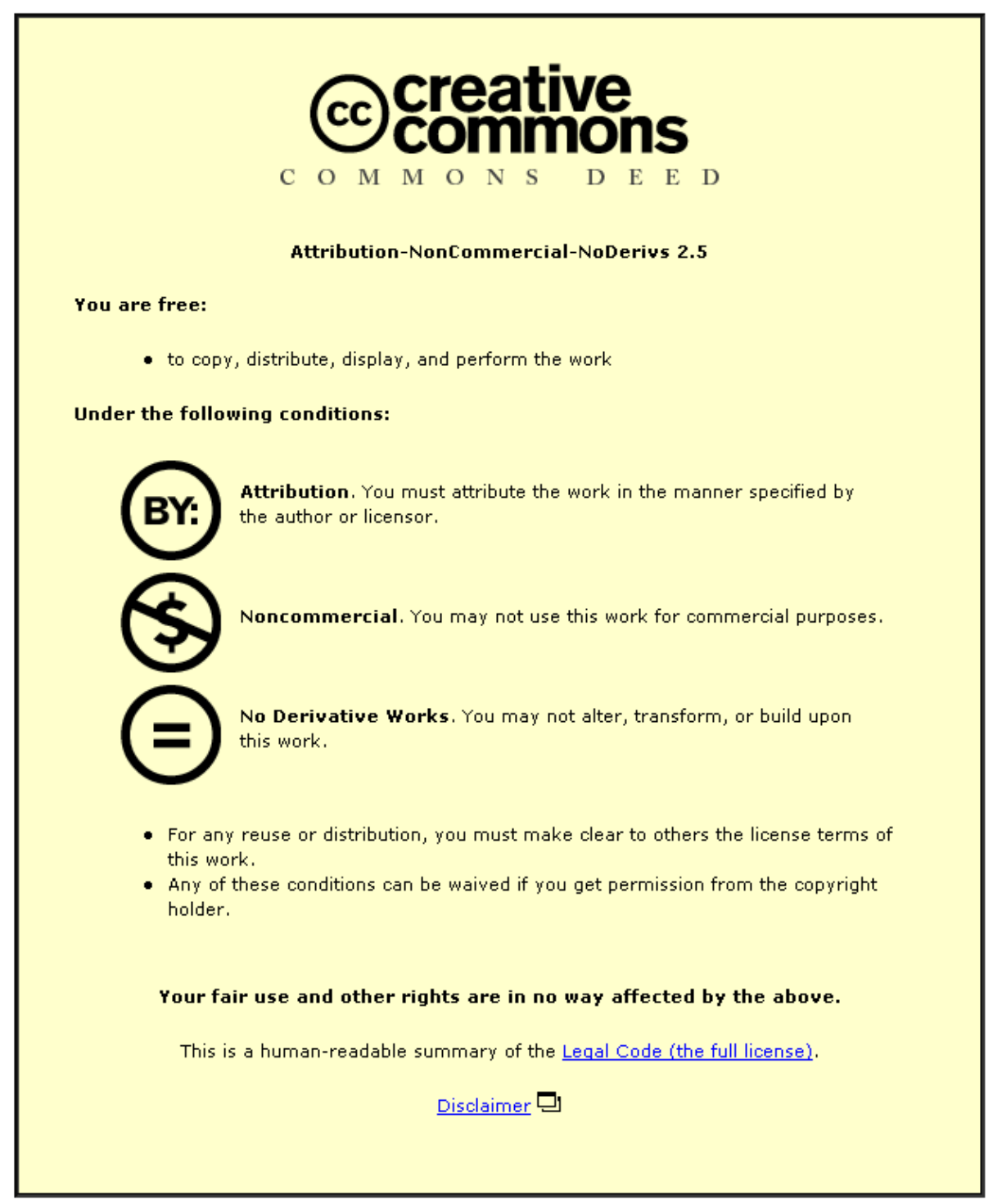

For the full text of this licence, please go to: http://creativecommons.org/licenses/by-nc-nd/2.5/ 


\section{A Framework for Filtering Web Accessibility Guidelines}

\author{
Rehema Baguma \\ Makerere University, \\ P.O.Box 7062, Kampala, \\ Tel. +256-41-4540628, \\ rbaguma@cit.mak.ac.u
}

g

\author{
Roger G. Stone \\ Loughborough \\ University, Leics, Le11 \\ 3TU, UK, \\ Tel.+44- 1509-222686 \\ R.G.Stone@lboro.ac.uk
}

\author{
Jude T. Lugega \\ Makerere University, \\ P.O.Box 7062, Kampala, \\ Tel.+256-41-4540628 \\ jlubega@cit.mak.ac.ug
}

\author{
Th.P. van der Weide, \\ Radboud University, \\ P.O. Box 9010, NL-6500 \\ ED Nijimegen, The \\ Netherlands, \\ Tel. +31-24-365 33 \\ Th.P.vanderWeide@cs.r \\ u.nl
}

\begin{abstract}
This paper first presents a framework for filtering the Web Accessibility Guidelines according to contexts of use. It then presents a prototype that implements the framework and explains an evaluation of the prototype.
\end{abstract}

\section{Categories and Subject Descriptors}

D.3.3 [Web Design]: Accessibility Guidelines.

\section{General Terms}

Design, Human Factors, Standardization

\section{Keywords}

Web Accessibility, Web accessibility guidelines, content filtration, context of use.

\section{INTRODUCTION}

The World Wide Web Consortium (W3C), governments and special interest groups have developed Web accessibility guidelines that provide guidance on how to develop or procure IT products and services that can be used by people with disabilities (PWDs). But many web based systems are still not accessible to PWDs [1, 2, 3, 4, 5, 6]. Presently, the most comprehensive, recognized and widely adopted Web accessibility guidelines is the Web Content Accessibility Guidelines (WCAG) by W3C [7, 8]. The WCAG have formed the basis of Web accessibility policy of many organizations across the world, are referred to in court cases concerning accessibility and are used as evaluation criteria by most automated evaluation tools [9, 10].

However many members of the target audience still find WCAG difficult to use $[8,11]$. One of the challenges faced is difficulty in getting the advice needed [12]. WCAG 1.0 has been criticized for being difficult in this respect for much of its potential audience.

\subsection{Web Page Component Context of Use}

This context of use organizes and presents accessibility guidelines according to components that constitute a Web page as a resource to hold information, how they are related (navigation) and how they are presented (user interface). The Web page organizes these elements into a functional resource.

Permission to make digital or hard copies of all or part of this work for personal or classroom use is granted without fee provided that copies are not made or distributed for profit or commercial advantage and that copies bear this notice and the full citation on the first page. To copy otherwise, or republish, to post on servers or to redistribute to lists, requires prior specific permission and/or a fee.

W4A2009, April 20-21, 2009, Madrid, Spain. Co-Located with the 18th International World Wide Web Conference.

Copyright 2009 ACM 978-1-60558-561-1\$5.00.
WCAG 2.0 which was developed to address limitations of WCAG 1.0 has also been criticized for being 'overlong', unreadable and impossible to understand [13, 14]. Some critics have recommended continuing with WCAG 1.0 [14].

This paper discusses a framework for filtering Web accessibility guidelines according to a context of use. The context of use is important for the usability of accessibility guidelines since they are used by different groups of people with different interests and skill base [8].

A prototype that implements the framework was developed and tested alongside the WCAG 1.0 guidelines. The results suggest that the framework is an improvement to the one view for all. Other than accessibility guidelines, the framework is also useful to any static online content if intended for various groups of users.

\section{A FRAMEWORK FOR FILTERING WEB ACCESSIBILITY GUIDELINES}

The framework for filtering Web accessibility guidelines organizes and presents Web accessibility guidelines such as WCAG according to contexts of use based on audience roles and other use case scenarios. The proposed contexts include: level of use, type of disability, Web page component and structure of the document. The purpose of the framework is to make the guidelines easier to use to find required advice. Instead of one view for all like the current structure of WCAG 1.0 and WCAG 2.0 , the guidelines can be organized into contexts of use/views according to user roles and or other use case scenarios as shown in figure 1 .

Figure 1 shows the four contexts of use and their sub contexts by which the Web accessibility guidelines can be organized and presented. It also shows that views can be combined such as techniques for navigation accessibility as shown in the rectangle with dotted borders. Section 2.1 to 2.4 describe each context and the role it plays in making the guidelines easier to use.

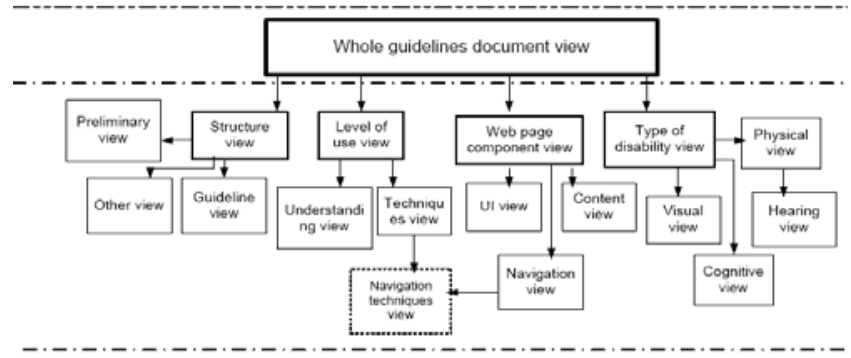

Figure 1. A framework for filtering Web accessibility Guidelines

The content of a Web page is the information provided on a Web page including text, images, video, audio or a combination. Content is accessible if it can be viewed and accessed by the majority of users including PWDs [15]. 
Web navigation is the method of getting around a given page, or moving within the website and onto other Web pages [15]. Common Web navigation tools include navigation menu, links, headings, which ideally can be activated by using either a mouse and or the keyboard. But for some PWDs this may require the use of their standard support technology.

The user interface of a Web page refers to the objects that the end user perceives and interacts with [15]. This covers the way in which navigational objects are represented, which interface objects activate navigation, the way in which multimedia interface objects are synchronized, which interface transformations take place and the presentation of tasks that require users to input information such as a survey form [16, 17].

Structuring accessibility guidelines according to content, navigation and user interface also increases the likelihood of developing more usable Web based systems [18]. Besides, interactive sites usually have more comprehensive user interface and navigation modules compared to content. Less interactive sites are more content oriented.

\subsection{Type of Disability context of Use}

Different disabilities cause different barriers on the Web. Additionally, different Web projects may have varying levels of accessibility requirements for different types of disabilities. However, WCAG 1.0 does not categorize and present guidelines according to type of disabilities. WCAG 2.0, mentions against each guideline, the disability (ies) it benefits but this is only done at guideline level. One cannot get at once all the guidelines about a particular disability.

The filtration framework shows how to organize and present Web accessibility guidelines according to types of disabilities that affect a person's use of the Web. The classification is based on the definitions of disabilities given in [19].

\subsection{Level of Use Context of Use}

According to a study conducted by Donelly and Magennis in 2003 [8], users of Web accessibility guidelines want information that is tailored to their roles and responsibilities. People involved in IT procurement need assistance in drafting the request for tender/proposal and assessing compliance with the agreed contract. IT project Managers need an accurate overview of accessibility problems and the implications of compliance to avoid them. Developers require detailed technical guidance and illustrative examples. The organization and presentation of available Web accessibility guidelines does not enable non technical stakeholders to easily find appropriate advice while developers lack guidance on how to humanize accessibility aspects of their systems. Consequently developers focus more on passing automated accessibility tests, which are technical oriented and less focused on usability for PWDs [9]. The filtration framework organizes and presents accessibility guidelines according level of use with two sub contexts namely: understanding the guidelines and techniques. Although WCAG 2.0 is split into 2 main documents based on the same concept, each of these is a separate document which means users have to move back and forth between the main guidelines page and the documents. The filtration framework presents both views in a single document through the level of use context.

The Understanding guidelines view is aimed at both developers and non technical stakeholders. The later need to gain an accurate overview of accessibility problems and the implications of compliance, while developers need an over all awareness to inform the integration of accessibility into the Web development process as well as determination of design implications. The techniques view provides developers with practical guidance and illustrative examples on coding accessible pages.

\subsection{Structure of the document Context}

This context organizes and presents the guidelines according to the logical organization of the guidelines. It has three sub contexts namely: preliminary content such as abstract, guideline which provides a per guideline view and other information which displays appendixes, references and acknowledgement. Instead of having peripheral content such as table of contents, abstract, references and acknowledgement displayed with the main guidelines content, this information can be displayed only when it is needed. The guideline sub view makes it easy to refer to a particular guideline while using the guidelines.

\section{A PROTOTYPE}

A prototype that implements the framework was developed using the WCAG 1.0 guidelines. We chose to test the framework on WCAG 1.0 because until 11th December 2008,

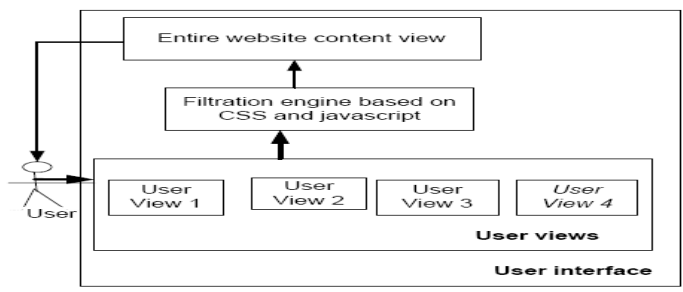

Figure 2: The architecture of the prototype

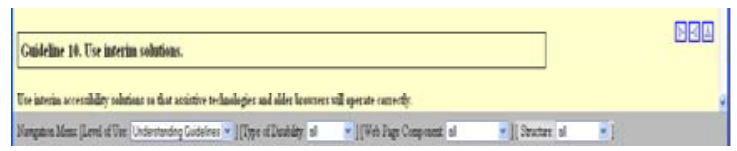

Figure 3: A snapshot of the prototype

WCAG 1.0 was still the stable and referenceable version of WCAG as was stated on the WCAG 2.0 overview page by 20th November 2008. The architecture of the prototype consists of three elements namely; user views, a filtration engine and the entire content view. The user views are the four-dimensional viewing opportunities based on the four contexts of use. The entire content view refers to the entire content of the guidelines before filtration. The filtration engine is what filters the entire content to obtain refined advice. The filtration engine is uses CSS and java script. CSS was used to package each context of use as a style sheet file, while java script applies the style sheet(s) on the entire content view to filter out required advice. The architecture of the prototype is presented in figure 2 .

To implement the prototype, the source code of WCAG 1.0 website was extracted and recoded to add CSS style tags, links to external style sheet files for the different contexts of use and the java script-script.

At the user end, he/she sees a large frame containing the guidelines document and a small navigation frame. The navigation frame offers a four-dimensional viewing opportunity based on the four contexts of use. Thus the user may select "techniques" (rather than "understanding") from the "level of use" menu. Each menu choice causes a small client-side script to run which dynamically selects a suitable style sheet to filter the display in the large viewing frame. A choice in one context may be combined with choices in other contexts. So for example 
the "techniques" choice could be combined with "visual" (rather than "hearing", "physical" or "cognitive") from the "disability" menu to give a display of techniques for visual impairment.

The filtration framework has a more optimal design for the static guidelines compared to the database driven design used by some accessibility guidelines like the Irish IT accessibility guidelines [10]. Figure 3 shows a snapshot of the prototype.

\section{TESTING OF THE FRAMEWORK}

Colwell and Petrie [20] noted that two of the key aspects that determine whether Web accessibility guidelines can be used efficiently and effectively are whether the organization and presentation allows the discovery of the required advice and whether the interface to the guidelines is usable. To test the two aspects about the proposed framework, the prototype was tested in parallel with WCAG 1.0 guidelines on a group of local developers and IT Managers as follows:

\subsection{Methodology}

The testing involved tasks on the 'raw' (WCAG 1.0) guidelines and the 'framework' guidelines. The tasks required participants to identify and document advice for addressing accessibility issues specified in the tasks. The tasks for each group were related to their roles in the Web development process. The task descriptions covered typical scenarios in which Developers and IT Managers might need to use the guidelines. For each task, participants were asked to rate the ease of completion. In addition participants documented their experience about the usability of the two sets of guidelines. Instead of using the same task for each set of guidelines, different tasks were given, but each testing the same aspect e.g. advice for different disabilities. The background color of the framework guidelines was changed to differentiate it from the 'raw' guidelines.

\subsection{Results: Web Developers \\ 4.2.1 Ease of Completion of Tasks}

As shown in table 1, tasks on the framework guidelines were completed with less difficulty compared to the tasks on the raw (WCAG 1.0) guidelines. On the task where participants had an option to choose the set of guidelines to use, 18 out of 20 preferred the framework guidelines citing easier navigation as the main reason for their choice. The high number of developers that completed task1 with difficulty is linked to the fact it was their first time and first task to use WCAG, and this became better as they went along as evidenced by results of task 3 and 5 .

\subsubsection{User experience with each website}

In addition to the task based questions, Web developers also documented their experience from using both sets of guidelines as follows:

They noted that the framework guidelines were; easy to navigate, easy to find required advice and with them they could control the amount of information displayed at a given time. One of them remarked that, "grouping the guidelines into those that apply to content, navigation, etc, is useful because any one focusing on any of these contexts will be able to find quickly required advice". For the raw WCAG 1.0 guidelines, participants noted that; it was difficult to find required advice and they could not control the amount of information displayed at a given time.

The testing exercise also generated general comments about how WCAG can be improved from the Developers' perspective namely; a search feature, illustrations and guidelines on users who do not hear and see at the same time.

Table 1. Ease of Completion of Tasks for Web Developers

\begin{tabular}{|c|c|c|c|c|c|}
\hline Guidelines & Task & & $\mathrm{npl}$ & etio & \\
\hline & & $\mathbf{A}$ & B & C & D \\
\hline $\begin{array}{l}\text { Framewor } \\
\text { k }\end{array}$ & $\begin{array}{l}\text { Task 1: You have been told that your company website is not accessible to people who are blind. Use the framework } \\
\text { guidelines (yellow background) to find out what extra development work is required to make the website accessible. }\end{array}$ & 6 & 7 & 7 & 0 \\
\hline WCAG 1.0 & $\begin{array}{l}\text { Task 2: You have been told that the audio clips on your company website are not accessible to people who are deaf. Use } \\
\text { the raw guidelines (white background) to find out what extra development work is required to make the website } \\
\text { accessible. }\end{array}$ & 5 & 3 & 9 & 3 \\
\hline $\begin{array}{l}\text { Framewor } \\
\mathbf{k}\end{array}$ & $\begin{array}{l}\text { Task 3: You have received complaints that people with disabilities cannot navigate your company website. Use the } \\
\text { framework guidelines (yellow background) to identify web design considerations for making website navigation } \\
\text { accessible to people with disabilities and document how you got there }\end{array}$ & 8 & 8 & 3 & 0 \\
\hline $\begin{array}{l}\text { Users to } \\
\text { choose }\end{array}$ & $\begin{array}{l}\text { Task 4: Results of the recent user survey indicate that people who have motor disabilities e.g. hand movement problems } \\
\text { have difficulties with the user interface of your company website. Use either of the guidelines to identify web design } \\
\text { considerations for making your website's user interface accessible to people with motor disabilities and document how } \\
\text { you got there }\end{array}$ & \begin{tabular}{l|l|l|l}
1 \\
1
\end{tabular} & 4 & 2 & 2 \\
\hline & $\begin{array}{l}\text { Task 5: Which set of guidelines did you use in task } 4 \text { and why? } \\
\text { All except two Chose framework because of: easier to find advice and could control the amount of content displayed. }\end{array}$ & & & & \\
\hline
\end{tabular}

Key: A-No Difficulty; B-Minor Difficulty; C-With difficulty; D-Did not Complete

Table 2. Ease of Completion of Tasks for IT Managers

\begin{tabular}{|l|l|l|l|}
\hline Task & \multicolumn{2}{l|}{ Completion } \\
\hline & A & B & D \\
\hline $\begin{array}{l}\text { Task 1: You are proposing to redesign your company website to make it accessible to people with disabilities. Management has } \\
\text { requested that you prepare for them an outline of special web design considerations that need to be met in the redesign process. Use } \\
\text { the framework guidelines (yellow background) to develop this outline and document how you got guidance. }\end{array}$ & $\mathbf{0}$ & $\mathbf{3}$ & $\mathbf{0}$ \\
\hline $\begin{array}{l}\text { Task 2: You have been tasked to write a request for proposal (RFP) for designing a website to make it accessible to people with } \\
\text { disabilities. Use the raw guidelines (white background) to find out what you need to include in the RFP and document how you } \\
\text { got guidance. }\end{array}$ & $\mathbf{0}$ & $\mathbf{8}$ & $\mathbf{0}$ \\
\hline
\end{tabular}


In addition, there were general remarks made about Web accessibility particularly in relation to the local environment namely; "It was good to know that there is such guidance one can use for wider usability, "these guidelines are good but a law should be put in place to enforce their implementation".

\subsection{Results: IT Managers}

\subsubsection{Ease of Completion of Tasks}

As shown in table 2, the task on the framework guidelines was completed more easily by more participants (7) compared to the task on the WCAG 1.0 guidelines (2) participants.

\subsubsection{User experience with each website IT}

They found the framework guidelines easier to find required advice using the navigation menu. While the WCAG 1.0 guidelines were difficult to use to get the advice needed.One noted "I found the raw guidelines harder to navigate because the user is assumed to know where a given piece of information is".

The IT Managers also made general comments about how WCAG can be improved from their perspective namely; a FAQs page, a summary of the guidelines, examples on how to apply the guidelines, a section on description of disabilities and tools used by PWDs, and legal implications.

Their general remark about the subject was that the Uganda Communications Commission should regulate national implementation of the WCAG guidelines.

\section{DISCUSSION:}

As per the results presented, developers and IT Managers preferred the framework guidelines due to the context based navigation menu compared to the one view for all used by most guidelines like WCAG 1.0 and WCAG 2.0.The test results confirmed that the context of use navigation menu makes Web accessibility guidelines easier to use to find required advice for the potential audience.

Although the framework was tested on WCAG 1.0, the approach is also useful for WCAG 2.0 which also has a one view for all. Besides, it is useful for other static web based content for any subject if intended for multiple classes of users.

\section{CONCLUSION \& FUTURE WORK}

Usability of Web accessibility guidelines such as WCAG can be improved by organizing and presenting them according to context of use. This can be achieved through classification and presentation of the content according to contexts of use based on audience roles and other use case scenarios.

In future, we shall test the framework on Web developers and IT Managers familiar with Web accessibility and WCAG guidelines. We will also extend the framework to include contexts of use for policy makers, another key target audience.
[1] Huang C.J. (2003). Usability of E-Government Web Sites for PWDs, Proc. HICSS03.

[2] Nielsen J. , Beyond Accessibility: Treating Users with Disabilities as People. Jakob Nielsens Alertbox, accessed on 5th Nov. 2006 from: http//www.useit.com /alertbox/20011111.html

[3] Takagi H. et al., (2006). Accessibility Designer: Visualizing Usability for the Blind. ASSETS04, USA.

[4] Disability Rights Commission (DRC), (2004). The web access and inclusion for disabled people. Technical report.

[5] Abanumy A.,., Al-Badi A., and Mayhew P.(2005). Egovernment website Accessibility: In-Depth Evaluation of Saudi Arabia and Oman. The Electronic Journal of eGovernment Volume 3 Issue 3

[6] Baguma et al., (2007). Accessibility of E-government Web Sites for PWDs in Uganda", In proc. Computer Science and ICT Conference, 2007, Nairobi, Kenya.

[7] Kelly et al., (2005). Forcing Standardization or Accommodating Diversity? A Framework for Applying the WCAG in the Real World, W4A2005, Chiba, Japan

[8] Donelly \& Maggenis (2003).Making Accessibility Guidelines Usable, LNCS 2615, pp. 56-67, 2003.

[9] Mline et al., (2005). Are guidelines enough? An introduction to designing Web sites accessible to older people, IBM Systems Journal, Vol 44, No 3, 2005

[10] Sloan et al., (2000)a. Contextual Web Accessibility Maximizing the benefit of Accessibility Guidelines

[11] Asakawa C. (2005). What the Web is Like If You Can't See It?, W4A 2006, Edinburgh, UK.

[12] Sloan et al., (2000)b. Accessible Accessibility, CUU '00 Arlington VA USA

[13] Pickard (2006). The WCAG 2.0: What a Whopper, retrieved from http://learningtheworld.eu/2006/to-hellwith-joe-clark/ on $5^{\text {th }}$ Jan. 2008.

[14] Clarke (2006). To hell with WCAG, retrieved from http://learningtheworld.eu/2006/to-hell-with-joe-clark/ on $10^{\text {th }}$ January 2008.

[15] Thatcher et al., (2002). Constructing Accessible Web Sites, web professional to web professional an Apress imprint.

[16] Shwabe \& Rossi, (1999). Developing Hypermedia Applications using OOHDM retr. from on 11- Jan.2008.

[17] Vanderheiden (2000). Fundamental Principles and Priority Setting for Universal Usability, CULl '00 Arlington VA USA

[18] US Depart't of Health \& Human Services-DHHS (2006). Research based Web design and Usability Guidelines

[19] Brewer,J.(ed.) (2005). How PWDs Use the Web, 2005, retrieved on 20th 2007 http://www.w3.org/WAI/EO/Drafts/PWD-UseWeb/Overview.html-use

[20] Colwell \& Petrie (1999). Evaluation of Guidelines for Designing Accessible Web Content, INTERACT'99

\section{References}

